\title{
An Evaluation of Applying Blended Practices to Employ Studio- Based Learning in a Large-Enrollment Design Thinking Course
}

\author{
Sydney E. Brown \\ Sarah Thomas Karle \\ Brian Kelly \\ University of Nebraska-Lincoln, United States
}

\begin{abstract}
DSGN110 was a multidisciplinary course teaching first year students enrolled in in a variety of majors about design thinking. The course is offered for the majors of architecture, landscape architecture, interior design, community and regional planning, along with computer science and business students. By blending face-to-face and online instructional strategies, desired practices and learning outcomes associated with the more intimate nature of studio-based learning and learning through action were scaled and achieved in the large enrollment course. The quantitative analysis of the pre and post survey revealed significant change across all constructs and the qualitative data analysis supported these findings, demonstrating that a blended course design utilizing collaborative technology platforms offered an innovative solution to teaching and learning in a manner reflective of a studio-based pedagogy.
\end{abstract}

Keywords: Blended learning; Studio-based learning; Design thinking; Mixed methods; Technology and learning; Educational technology

\section{Introduction}

Design thinking "puts the tools (of design) into the hands of people who may never have thought of themselves as designers and applies them to a vastly greater range of problems." (Brown, 2009, p.13.). The approach has received attention in business, engineering, architecture, and design majors in universities because the process can change how students' learn and problem solve (Dym, Agogino, Eris, Frey, \& Leifer, 2005; Fricke, 1999; Nagai \& Noguchi, 2003). With industry demand for a more creative labor force capable of cross- and inter-disciplinary collaboration, University of Nebraska-Lincoln created Design Thinking 110 (DSGN110), a required course for all students in the College of Architecture and the Jeffrey S. Raikes School of Computer Science and Management.

Design thinking is generally defined as an analytical and creative process engaging a person in opportunities to experiment, create and prototype models, gather feedback, and redesign (Razzouk \& Shute, 2012). Consequently, the essential elements of studio-based learning - learning by doing, collaborating with the environment (other students, instructors, and external stakeholders), and re-doing until an agreement is reached among stakeholders (Lackney, 1999) is 
considered an essential approach for effective student learning of design thinking concepts. However, the studio environment typically has a small student to teacher ratio and requires a permanent working space, making studio-based learning a difficult pedagogy to apply in a large enrollment course. To surmount this challenge, and meet the charge to engage a larger university community in a supportive learning environment (Boyer \& Mitgang, 1996) blended learning practices supported by collaborative technologies were used to provide a studio-based pedagogy to a large enrolment course. To evaluate the effectiveness of the course design with respect to student learning of design thinking concepts, both quantitative and qualitative methods were used, which is in line with Pombo and Moreira's (2012) recommendation.

\section{Theoretical Foundation}

Social constructivism formed the theoretical foundation for the design of the course. From an epistemological perspective, students constructed their own understandings but that they did so in social contexts and the interactions with others in those contexts were integral to learning. In general, constructivist learning environments have the following characteristics: a focus on big concepts, use of primary sources, authentic assessment, problems of emerging relevance to students, students' points of views are sought and valued, and collaborative learning is employed (Schunk, 2011). This theoretical framework is compatible with studio-based learning - the core of design curricula.

Studio-based learning is characterized by its establishment of a culture, or creative community, created by a group of students and studio teachers working together for periods of time. It is also a mode of teaching and learning wherein students and teachers interact in a creative and reflective process. It may also be a program of projects and activities where content is structured such that it is "learning in action" or authentic, in that students address real-world problems, often in an effort to positively contribute to their local communities.

\section{Literature Review}

The literature related to blended learning has expanded greatly in the past five years. However, there is a relatively limited literature on course design using blended learning methods for studiobased courses.

\section{Studio-Based Learning}

The goal of the course was to introduce freshman students to divergent and convergent methods of thinking in a design process. However, design can be ubiquitous; it is the creation of meaning, either in physical/material form or in less tangible outcomes likes policies, plans, and programs. According to Razzouk and Shute (2012, p. 336) design is "iterative, exploratory and sometimes a chaotic process," that encapsulates both how the designer sees and therefore how he or she thinks. The design process covers the "cognitive operations" of problem solving that includes "generation, exploration, comparison and selection" of potential solutions (Razzouk \& Shute, 
2012, p. 336). For the above reasons, there is considerable divergence in the design world as to how to approach the process of design. Some scholars argue for a linear, rational, and deliberate set of steps and others for something more emergent and improvisational (Ralph \& Wand, 2009). In either case, the designer is someone who employs a design process to specify the object, arrange the components, and satisfy requirements using a set of steps that together are the design process (Cross, 2004). Despite the range of scholarly debates on the design process itself studio-based pedagogy is considered the best method for teaching design.

Research related to design education suggest that a studio-based pedagogy is the best method for cultivating students' identities as designers, developing their conceptual understanding of design, the design process and fostering their design thinking abilities (Schön, 1983). Studio-based learning is used in the fields of architecture, design, engineering, and creative and performing arts. Although diverse in its forms, studio-based learning focuses on learning through action (applied learning) and developing an assessable creative and/or design process, performance or product. The studio is a place where students learn by doing, a venue for hands-on learning that requires students to take an active role in engaging with and incorporating distinct components of the curriculum into a comprehensive project (Yocom, Proksch, Born, \& Tyman, 2012).

Studio-based learning evolved from previous studies of the socio-cultural constructivism thread of constructivist learning theory. Principle elements from these previous works included learning by doing, collaborating with the environment (other students, instructors, and external stakeholders), and re-doing until an agreement was reached among stakeholders (Lackney, 1999). Within the disciplines of Art, Architecture and Design, the role of studio is valued highly and considered intrinsic to learning. In Cuff's $(1992$, p. 122) study, the author defined 'studio' as "typically a creative community created by a group of students and a studio teacher working together for a period of time." The studio is a physical or constructed environment in which the teaching and learning can take place. The programs of projects and activities is structure to enable learning in action through a mode of teaching and learning where student and studio teachers interact in a creative and reflective process.

Significant enhancements to learning have been found in various studies. According to Boyer and Mitgang (1996) Studio-Based Learning "is really about fostering the learning habits needed for the discovery, integration, application and sharing of knowledge over a lifetime". Moreover, Cuff (Cuff, 1992) noted the positive effects of peer reviews, called "desk critiques," where the problem solving strategies of the better students influences the other students' evolving habits throughout the academic period. Observational data in research in architecture education by (Allen, 1980), noted that students learned technical skills more effectively when engaged in a problem solving challenge that required the selection and application of those skills and knowledge in the process as opposed to alternative instructional delivery techniques such as lecture or reading assignments with no practical application.

\section{Blended Learning Methods}

The adoption of blended courses has been driven by a need to address lack of student success in large-enrollment courses, surmount constraints of physical classroom space, to render courses 
more accessible to increasingly diverse student populations, and to reduce costs (Graham, Woodfield, \& Harrison, 2012; Jarmon, 2009; Moskal \& Cavanagh, 2013; Twigg, 2003). Although there is no generally accepted definition of blended learning (Picciano, 2013), within the scope of this article, blended learning (BL), refers to a course design that replaces some amount of traditional seat-time with technology-supported activities. This type of course may also be referred to as a "hybrid" or "replacement" model in the literature.

Garrison and Vaughan (2007) describe BL as a "thoughtful integration" of face-to-face and online instructional strategies and Glazer (2012) proposes that students spend more time on task in blended courses. Although time on task alone does not correlate strongly with performance (Guillaume \& Khachikian, 2011), deliberate practice, a form of structured time-on-task, does (Ericsson, Krampe, \& Tesch-Römer, 1993).

Integrating face-to-face and online activities necessitates additional structure in order to account for course contact hours and ensure what students do outside of class is tightly related to what they do in class. Because of this, students may spend more time-on-task in more effective ways than in traditional face-to-face or fully online courses. This may help account for Moskal, Dziuban, and Hartman's (2013) finding that blended courses have the highest success and lowest withdrawal rates despite the mixed evidence in terms of learning outcomes when blended, online, and face-to-face courses are compared (Means, Toyama, Murphy, Bakia, \& Jones, 2010) a finding suggesting instructional strategies and techniques account for learning rather than mode.

\section{Large-Enrollment Courses and Studio-Based Learning}

The studio is a relatively rare pedagogical approach in university environments, and it has been described as a particularly powerful method for teaching students to identify, assess, and generate solutions for complex problems (Boyer \& Mitgang, 1996). It offers students the opportunity to build disciplinary vocabulary and lean new technical skills, and it introduces a practitioner's perspective in its approach to addressing complex topics (Yocom et al., 2012). One of the key characteristics of successful studios is reasonable class-sizes or groups (Zehner et al., 2010). Because studio-based learning is heavily reliant on direct interaction between students and their instructors as well as between students, both in collaborative work and in critique, large class sizes are perceived as prohibitive to enacting studio-based pedagogies despite their importance to learning in design, art, and architecture. However, like many colleges, those of architecture and design are facing increased pressures to engage a larger university community in a supportive learning environment (Boyer \& Mitgang, 1996) and BL may provide the framework for scaling studio-based approaches.

\section{Instructional Design}

Fink's (2013) approach was used to guide the instructional design of the course. This approach is based on a traditional Analyze, Design, Develop, Implement, and Evaluate (ADDIE) model, but is an approach supportive of deep analysis of situational factors and their impact. For example, in 
order to gain acceptance for the large-enrollment course by its constituent communities for which studio-based learning remains the gold standard, key characteristics of studio-based learning such as smaller class size, direct interaction, dedicated physical space, and learning through action had to be manifested in the course design. The learning outcomes associated with the more intimate nature of studio-based learning were scaled and achieved in the large-enrollment course by using proven instructional techniques to support those outcomes in both face-to-face and online environments.

\section{Attaining a Reasonable Class Size Effect}

Zehner (2010) asserts one of the key characteristics of a successful studio is a reasonable class size in order to ensure direct interaction between students and their instructors as well as with each other. To achieve this goal, the 170 students enrolled in DSGN110 were divvied into 10 sections. An architecture learning community made up one section. Remaining students were randomly assigned to the other nine. However, a manual review of the distribution of students was conducted to ensure students from the Raikes School were evenly spread among the nine randomly assigned sections as requested by the school in order to give these students practice in cross-disciplinary team work. Additionally, this group of students brought a beneficial set of characteristics and skills to their respective teams.

Raikes School students live in a learning community and they are academically oriented high achievers with ACT scores of 33 or better and graduate in the top 10 percent of their high school classes ("Jeffrey S. Raikes School of Computer Science and Management," n.d.). Moreover, they must also have demonstrated leadership skills and are more technologically proficient with many possessing considerable skill in computer programming before they begin college classes.

To further shrink the sense of the class size, each 18-student section was divided into learning teams of six. In this way, direct interaction among students and between students and their instructors were more strongly supported.

\section{Allocating Student Time to Support Direct Interaction}

Strategic use of multiple instructional modes was employed in the three credit hour course. Its twice-weekly face-to-face meetings where all 165 were scheduled to meet synchronously were reduced by 50 percent. Half the class met on Tuesdays and the other half met on Thursdays. During this time, lead instructors often made short full-group presentations ( $20 \mathrm{~min}$ ), then spent the remainder of the time circulating among the learning teams giving feedback on projects, asking guiding questions, and interacting with students in other ways. During the other half of direct instructional time, Google Hangouts, a free web conferencing tool, was used to create a virtual meeting place for the learning teams and their TA's.

Direct interaction of each team with its designated TA lasted one-third of the time of the normal class time. For the other two-thirds of the allocated time, teams were accountable for work on team projects and assignments. To work with each other, teams were allowed to use online or 
face-to-face modes. On Mondays, Wednesdays, Fridays students worked together as needed or completed individual assignments on their own.

The frequency with which learning teams met with each other and with their TA's and instructors in a small group required tight coordination and attentiveness by the teaching team, but helped to develop the sense of a creative community in which students work with each other and their instructors (Cuff, 1992).

\section{Creating a Dedicated Physical Space}

Because an important part of studio-based learning is having a dedicated physical space, DSGN110 was allocated a large open learning space and equipped with double-sided whiteboards, tables and chairs. The tables can also be used as whiteboards and all furniture has wheels to facilitate rapid reconfiguration and hands-on learning. Students sat with their learning teams, having both a table and white board with which to create a more private space within the larger dedicated space.

\section{Learning through Action}

The course consisted of five scaffolded modules, each emphasizing a particular phase of the design thinking process and centered on the completion of a team project. The projects aimed to give students practice with the cognitive aspects of problem solving (Razzouk \& Shute, 2012) and included collaborating with the environment (other students, instructors, and external stakeholders), and re-doing until an agreement was reached among stakeholders (Lackney, 1999).

Outside of class times, students individually read, watched, or listened to source materials about design, and took quizzes to ensure they were familiar with concepts and terms that would be addressed in the coordinated Google Hangout synchronous sessions. Students also met with their learning teams through Google Hangouts and face-to-face to work on module projects. During the single face-to-face session each week, lead instructors, of which there were two, would address key concepts, answer questions, give feedback, and observe group dynamics as students completed learning activities.

\section{Supporting Technologies}

In addition to Google Hangouts, a G+ community, Google Drive, and Blackboard Learn were leveraged to manage the course and its demands. Assignments, student project documentation, and all course information was created and managed using Google Docs, Spreadsheets, and Slides in Google Drive. This allowed the instructional team to work together to rapidly generate content and avoid the version control problem and save the time required to merge versions described by (Vickers, Field, Melakoski, \& others, 2015, p. 64). Moreover, it ensured students had access to the most recent version of documents in a networked device independent format. However, when using a variety of collaborative platforms, finding particular types of items can be challenging. 
This problem was minimized by using Blackboard as students' "home-base." There they found direct links to the G+ community, the syllabus and other Google Docs describing assignments and other resources. Blackboard was also used to manage grades and assignment submittal and feedback. To further reduce confusion, clear naming conventions were used to facilitate locating and sorting documents within Google Drive.

\section{Methodology}

The initial term in which the course was taught was an opportunity to set a baseline from which to iterate and make refinements based on formative evaluation (Fain, 2005) much like the testing phase of the design thinking process. Also akin to the design thinking process was the need to make use of both quantitative and qualitative data. Because it was anticipated that the course content and activities might change based on what was learned over the term, a convergent mixed methods design was determined (Creswell \& Plano Clark, 2011) to be the best methodological approach to address student acquisition of design thinking constructs. Specifically, after receiving permission from the Institutional Review Board (IRB), quantitative data were collected via a pre and post survey (Qualtrics, 2013) and qualitative data were collected from students' guided selfreflections for the purpose of corroboration (Bryman, 2006; Creswell \& Plano Clark, 2011). Participant privacy was secured by having a non-instructor manage the data and remove identifying information from files to be analyzed. Additionally, encryption software (TrueCrypt, 2014) was used to secure the drive on which data that contained identifying information were stored.

\section{Participants}

There were 170 students enrolled in the course. Five withdrew and 165 were retained for the term. Of these, 70 completed both the pre- and post- online surveys as well as the guided selfreflections.

\section{Quantitative Data}

The pre-survey was done during the first two weeks of the term and the post-survey during the final two weeks. Survey items were identical and measured self-reported change with respect to the following constructs:

- Human-centered / Empathy

- Thinking by doing / Prototyping and Testing

- Teamwork

- Problem Definition

- Creative Confidence 


\section{Survey Design and Testing}

Although Stanford administers a survey as part of its Executive Education Design Thinking Boot Camp ("Design Thinking Boot Camp: From Insights to Innovation," 2015), it is not publically available and the team was unable to locate a valid and reliable survey preceding the start of the course. Consequently, items representative of the constructs and priorities from the perspective of the curriculum team and lead instructors were developed and underwent several editing cycles based on feedback from faculty and teaching assistants before being piloted with a small number of high school students participating in a summer design workshop. Because of their interest in design and high-school standing, they were considered representative of the students who would be taking the upcoming course.

The survey items were presented in clusters according to the scale to which they belonged and after each collection of items, students were presented with a text-area box and asked to identify anything about the question items they found hard to understand. Interestingly, despite having had several architecture students extensively review the question items along with the instructional team, many of the high school students reported difficulty understanding the meaning of key words in several items. The face validity of the survey was considered compromised and statistical analyses were not run. Instead, the meager time remaining before the start of the course was spent simplifying the language of several items.

\section{Survey Administration}

The pre-survey was administered August 2013 through a web interface and available to participants during the first two weeks of classes. The post survey took place in December 2013 and was also web-based and available to students during the last two weeks of classes.

\section{Survey Content}

Survey items aimed to get at students' self-perceptions related to their degree of or competency with the broad constructs representing desired course outcomes (Appendix A). The scale clusters were as follows:

(1) Empathy - Ability to understand others and the systems/process in which they operate.

(2) Ideate/Prototype - Ability to use multiple techniques to inspire a complete range of ideas.

(3) Teamwork - Ability to work with others to generate ideas and complete projects.

(4) Define - Ability to synthesize deep insights based on a complete system.

(5) Creative confidence - Empowered to take a position, maintain an optimistic stance, and not fear failure. 


\section{Quantitative Data Analysis}

In addition to reliability analysis and descriptive statistics, a paired-sample t-test in SPSS (IBM Corp., 2013) was used to assess changes between the pre and post scores both overall and by subscale of the 70 participants who completed both the pre and post survey. Effect sizes were generated.

\section{Qualitative Data Collection}

The qualitative data consisted of the guided self-reflections written by each student over the course of the term. To choose which cases to analyze, the results from the paired sample t-test were used to select cases within one standard deviation of the overall mean for representativeness (Teddlie \& Yu, 2007). The reflections were guided using Ash and Clayton's Articulated Learning model (2004) (Appendix B).

The procedure was as follows:

(1) Identify all cases within in each of the 10 course sections which were within 1 SD of the t-test mean

(2) Remove cases in each section grouping lacking any of the guided self-reflections

(3) From each section grouping, select three of the remaining cases at random

Not all sections had three cases which met all the requirements, resulting in 27 cases instead of 30 cases.

\section{Qualitative Data Analysis}

Analysis of the open-ended responses to the student evaluation consisted of thematic coding using MAXQDA (2011) with respect to empathy, ideate/prototype, define, creative confidence, and teamwork. The guided self-reflections were prepared for analysis by removing student and instructor identifiers and saving them as PDFs which were then divided between two of the course instructors for coding.

For the qualitative analysis of the guided reflections, a typological approach (Hatch, 2002, p. 153) was employed using the conceptual constructs the course aimed to teach.

\section{Results}

\section{Survey Constructs and Reliability}

Chronbach's alpha was used to measure the internal consistency of the scale items with values exceeding .70 considered acceptable (DeVellis, 2011). 
Table 1. Survey Constructs and Reliability

\begin{tabular}{llll}
\hline Construct & Definition & $\begin{array}{l}\text { Number of } \\
\text { Items }\end{array}$ & Cronbach's Alpha \\
\hline Empathy & $\begin{array}{l}\text { Ability to understand others and the systems } \\
\text { and processes in which they operate. }\end{array}$ & 6 & .778 \\
Ideate/Prototype & $\begin{array}{l}\text { Ability to use multiple techniques to inspire a } \\
\text { complete range of ideas. }\end{array}$ & 6 & .802 \\
Define & $\begin{array}{l}\text { Ability to synthesize deep insights based on a } \\
\text { complete system. }\end{array}$ & 4 & .825 \\
Creative Confidence & $\begin{array}{l}\text { Empowered to take a position, maintain an } \\
\text { optimistic stance, and not fear failure. }\end{array}$ & 10 & .801 \\
Teamwork & $\begin{array}{l}\text { Ability to work with others to generate ideas } \\
\text { and complete projects. }\end{array}$ & 3 & .705 \\
\hline
\end{tabular}

\section{Descriptive Statistics}

Seventy-seven percent of the participants were in their first year and most (46\%) were architecture majors with interior design (17\%) and computer science $(10 \%)$ making up the other two largest groups. Eleven other majors were represented (Table 2). 
Table 2. Demographic Characteristics of Participants $(n=70)$

\begin{tabular}{|c|c|c|}
\hline Characteristic & $\mathrm{n}$ & $\%$ \\
\hline \multicolumn{3}{|l|}{ Gender } \\
\hline Male & 31 & 44 \\
\hline Female & 37 & 53 \\
\hline Unreported & 2 & 3 \\
\hline \multicolumn{3}{|l|}{ Standing } \\
\hline $1^{\text {st }}$ year & 54 & 77 \\
\hline $2^{\text {nd }}$ year & 12 & 17 \\
\hline $3^{\text {rd }}$ year & 4 & 6 \\
\hline \multicolumn{3}{|l|}{ Major } \\
\hline Advertising \& Public Relations & 1 & 1 \\
\hline Computer Engineering & 3 & 4 \\
\hline Computer Science & 7 & 10 \\
\hline Electrical Engineering & 2 & 3 \\
\hline Global Studies & 1 & 1 \\
\hline Actuarial Science & 2 & 3 \\
\hline Business Administration & 2 & 3 \\
\hline Economics & 2 & 3 \\
\hline Mechanical Engineering & 1 & 1 \\
\hline Marketing & 1 & 1 \\
\hline Architecture & 32 & 46 \\
\hline Interior Design & 12 & 17 \\
\hline Landscape Architecture & 3 & 4 \\
\hline Textiles, Merchandising and Fashion Design & 1 & 1 \\
\hline \multicolumn{3}{|l|}{ Program } \\
\hline Architecture & 47 & 67 \\
\hline Arts \& Sciences & 8 & 11 \\
\hline Business Administration & 7 & 10 \\
\hline Engineering & 6 & 9 \\
\hline Journalism \& Mass Communications & 1 & 1 \\
\hline
\end{tabular}

\section{Paired-Sample t-Test}

A paired-samples t-test was used to determine whether there were statistically significant mean differences between participant self-ratings of design thinking constructs at the start of the course as compared to the end of the course. Overall, participants showed significant change across all six constructs, $\mathrm{t}(69)=4.73, \mathrm{p}<.001, \mathrm{~d}=.57$. A large effect size was found for Ideate/Prototype (.90), while Empathy (.58) and Creative Confidence (.42) generated scores in the medium range (Cohen, 1988). Full results are found in Table 3. 
Table 3. Difference between Pre and Post Measures of Design Thinking Constructs

\begin{tabular}{|c|c|c|c|c|c|c|c|}
\hline \multirow[b]{2}{*}{ Construct } & \multirow{2}{*}{$\begin{array}{c}\text { Pre-Survey } \\
\mathrm{M}\end{array}$} & \multicolumn{3}{|c|}{ Post-Survey } & \multirow[b]{2}{*}{$t(69)$} & \multirow[b]{2}{*}{$p$} & \multirow[b]{2}{*}{ Cohen's $d$} \\
\hline & & SD & $\mathrm{M}$ & SD & & & \\
\hline Empathy & 70.08 & 13.84 & 78.14 & 11.50 & 4.77 & .000 & .58 \\
\hline Ideate/Prototype & 65.06 & 15.41 & 76.05 & 13.04 & 7.44 & .000 & .90 \\
\hline Define & 70.04 & 16.44 & 75.34 & 14.36 & 2.68 & .009 & .32 \\
\hline Teamwork & 69.54 & 18.07 & 73.66 & 14.73 & 2.03 & .046 & .25 \\
\hline $\begin{array}{l}\text { Creative } \\
\text { Confidence }\end{array}$ & 68.81 & 13.05 & 74.68 & 14.83 & 3.45 & .001 & .42 \\
\hline Overall & 68.71 & 12.80 & 75.57 & 11.28 & 4.73 & .000 & .57 \\
\hline
\end{tabular}

Note. Effect size is based on the average SD from two means, which corrects for dependence between means using Morris and DeShon's (2002) equation 8.

\section{Qualitative Findings}

The qualitative data from the guided self-reflections was coded into six categories aligned with the five major constructs measured by the pre and post survey: creative confidence, human centeredness/empathy, defining/reframing, ideation, thinking by doing/prototyping/testing, and teamwork.

\section{Creative Confidence}

Overall, creative confidence for these students is about not being afraid to fail - of actually coming to believe that failure is a useful part of the creative process.

"Contrary to my initial belief, I've learned that failure is often the only way to achieve something truly successful. Being a stereotypical honors student in high school, failing was the worst of all possible scenarios for me for the majority of my schooling. However, through my experience so far in d.Think, I've become more and more aware that failure is an integral part of design as well as life."

Moreover, students recognized that failure did not mean one wasn't creative, but rather that creative success requires persistence and can be improved with technique and practice.

"This is important because before, I had the preconceived notion that creativity sprung out of one good idea. I assumed that some people are just inherently more creative than others and that this creativity provided spontaneous good ideas that for the most part worked out on the first attempt."

"Creativity isn't necessarily innate, but it can be learned." 


\section{Teamwork}

A main aim of the course was to explicitly instruct students with respect to being effective team members. Particular attention was paid to valuing feedback and different perspectives upon which better ideas could be crafted. Within this major category, several sub-themes emerged, most notably the idea that a team is stronger than any one individual because of its ability to combine the strengths and minimize the weaknesses of individuals.

I wrote the team contract for our team and as a group we talked about each other's strengths and weaknesses. At this point I realized how important this was because we delegated each person's role in the work for the module based on each individual's strengths.

Over the course of this module, I learned a lot more about my strengths and weaknesses and how they can help and hinder my participation in a group. Generally I have considered myself good at the more technical aspects of projects. For this module, I had to accept the fact that I was not going to be the strongest in this capacity.

Some students identified themselves as leaders and others seemed to recognize the need for leadership and then fill that role, realizing that they too, needed to listen and reach out to others. Most notable was the recognition that getting their teammates to take action took inspiration and that in order to inspire, one needed to understand their teammates' perspectives, which required empathy.

Learning empathy was the beginning of understanding how to be a good leader. If I can understand people, then I can inspire them. I first learned how to understand people when designing something for them but then I was also able to understand how empathy can be applied to relationships and then to leadership. I was able to understand my team and then figure out ways to inspire them.

\section{Ideation}

In general, students exhibited a change from believing that their first ideas were their only or best ideas to the recognition that any idea could be made better through the use of techniques such as prototyping, brain-storming, and seeking the cause of the problem for which the solutions were being generated. Some students mentioned the need to keep ideas organized so they could be revisited or combined with other ideas to further improve the solution.

I learned that latching onto the first idea for a design is not always the best choice. For me, this was a little counterintuitive because in high school we are told that when choosing answers on a test our first guess is probably correct and that second guessing may just be a sign of overthinking. However, in design, I don't believe this applies.

I learned that while thinking of ideas on how to solve a problem, the key is to try to come up with a lot of designs that are out of the ordinary and weird, yet are still possible. Once 
there are a good number of different designs, each taking different approaches to solve the problem, then find the best parts of all the ideas and combine them into one design.

\section{Empathy}

When writing about the empathy stage of the design process, the focus was placed on the need for user perspectives in order to design effective solutions. Students found this challenging and were initially inclined to interpret problems from their point of view only, but after instruction in interviews, observation, and techniques for getting to the root of problems, several students recognized their tendencies and described how what they learned impacted their approach to design.

"We had to solve the problems that the people we interviewed shared. I can be super biased, and one of the challenges was letting go."

"I want to be able to see things from other people's perspectives sooner than I have in the past."

"I learned this when I deepened the grade of empathy, by using the questions 'why' and 'how'. That made me able to notice the real motivations of some opinions, and if the solutions were really universal."

One student described how learning the skills of empathy in design helped during a math study group.

Although I wasn't necessarily designing for my friend, it make a huge impact when I was able to understand where he was coming from. There were three steps of empathy that the field guide talked about: Immerse, Observe, and Engage. Without even realizing it, I found myself going through these three steps during our math study session. [...] By doing these three things I was able to understand where he was coming from a lot better and also figure out the best way to approach helping him.

\section{Defining and Reframing}

Students found defining and reframing to be difficult, but with experience and failure, came to realize that constraints and clear problem definitions are key to generating ideas and assessing the effectiveness of the solution.

"Defining your purpose helps to understand where you're coming from and where you hope to go."

"I didn't realize the work that goes into framing the problem."

Typically, constraints are these chains that limit your thinking. In the case of design thinking, however, constraints are the model for the final model that you want to build; it's what makes the product desirable and feasible at the same time. 
They came to understand that deep analysis, prototyping, and testing are essential to refining the problem they were trying to solve and eventually lead to a more effective solution.

I had to learn to look closely into an idea, like ours, and to see the details of its function and how it would work in different settings, and with different users, and for different types of uses, and such. This was how systems thinking related to refining our idea to make it better, more useful, and still unique for this module.

The experiential aspect of failure and starting over was instrumental to one student's realization of how effective the design thinking tools could be.

Having our project turned down meant we would have to start the whole work again, but in the next time I decided to do paying attention to all the elements involved in making a good design solution. That's when I started asking myself many 'why's', and deiced to analyze and invest in prototypes. Just by doing these things I found out how they are valuable. Our project became way more solid, and I would never have discovered these tools if someone else had just told me that.

\section{Thinking by Doing}

Thinking by doing in the form of failing early and often as well as creating and testing prototypes was counter-intuitive for some students, but revealed assumptions and overlooked details for most.

I learned that the faster you start to build prototypes, the faster you can find the flaws that need to be addressed that may not have been obvious while initially discussing an idea. This was a harder concept for me to learn because I like to plan extensively before jumping into a project. I'm the kind of person who outlines their essays extensively before actually starting to even write them. It seemed almost counterintuitive to me to create something that was very likely going to fail. To me, that seemed like a waste of time. Nevertheless, I think this module finally helped me grasp and embrace the need to prototype early and often.

Prototypes help to test the product in real conditions, and I also learned how the real conditions clarify a lot of lacks in our project. I learned that, without the real-condition test, we end up making a lot of assumptions about our project, even if we don't notice it.

Students also learned that low-res prototypes help spark ideas for developing more robust prototypes.

We thought we would have a hard time prototyping a light-up carpet. We didn't know how we would go about portraying the final product. So we started small, and just made a simple paper version first, then we wove paper strips together to show the tiling effect. We 
then eventually moved up to our carpet and Christmas lights to combine all the functionalities we wanted our product to display.

\section{Presenting and Communicating Solutions}

Although presenting and communicating ideas to outside audiences was not part of the survey, or the constructs the team set out to measure at the start of the term, students identified the critiques as important learning activities. In fact, they realized that attempting to communicate their solutions to others was a test of their ideas and essential to their maturation as designers.

The idea was clear to us, because we developed it, but they did not understand what they were supposed to do. Another group had a similar presentation that was on a smaller scale. The professor reacted more positively to this because it was more understandable and left more time for explanation.

I've come to see what the public can act as an amazing jury and idea pool, being that they really are your client and biggest critic, will serve as a good survey audience to see the feedback you need before you get too deep into production and finalizing of your ideas by disregarding what the public wants as a whole.

This learning matters because I will be making many a presentation throughout my life. If I have any hope of being an effective employee, I have to be able to communicate to executive staff what I've been doing with my time. Even if I were a genius I could go unnoticed without the ability to communicate my abilities to others, or make my abilities useful.

\section{Conclusion}

\section{Blended Course Development}

\section{Time Allocation}

For the students and faculty participating in the course, the blended methods utilizing collaborative technology platforms offered an innovative solution to teaching and learning in a manner reflective of a studio-based pedagogy. Although the course design required great care and attentiveness from the entire teaching team it had the effect of helping to create a "reasonable class-size" for supporting student-student and instructor-student interactions. Because this course focused on a design process that is relatively new to industry and newer still to academia, additional work identifying the best course material to support the learning outcomes and enhance the blend of both synchronous and asynchronous teaching methods is needed. Furthermore, the oscillation, which refers to having half the students on Tuesdays and the other half on Thursdays for a full three hours makes it difficult to keep students in sync and to integrate online and face-to-face activities. With the Fall 2015 edition of the course, consideration is being given to dividing both Tuesdays and Thursdays such that each group has 
class for 90 minutes instead of 3 hours. In this way the seat-time replacement will remain $50 \%$, but it will eliminate the oscillation effect and thereby better support the integration of face-toface and online activities.

\section{Instructional Fidelity}

With $11 \mathrm{TA}^{\prime} \mathrm{s}$, it was difficult to ensure fidelity of instruction across sections. This issue may be addressed as students who have taken the course move through the program and become TA's themselves. However, upper-level students for whom the course was not available have asked for a course in design thinking and consideration is being given to how an upper level design thinking course might prepare future teaching assistants.

\section{The Blended Design Supported Studio-Based Learning Pedagogy}

The blend of both synchronous and asynchronous teaching methods fostered an open, blended learning environment, extending the traditional boundaries of applied learning in time and space. Central elements of studio-based pedagogy include learning by doing, collaborating with the environment (other students, instructors, and external stakeholders), and re-doing until an agreement was reached among stakeholders (Lackney, 1999). "Learning by doing" or "thinking by doing" and "iteration" were measured throughout the semester and the experiential aspect of failure and starting over was instrumental to one student's realization of how effective the design thinking tools could be.

Having our project turned down meant we would have to start the whole work again, but in the next time I decided to do paying attention to all the elements involved in making a good design solution. That's when I started asking myself many 'why's', and deiced to analyze and invest in prototypes. Just by doing these things I found out how they are valuable. Our project became way more solid, and I would never have discovered these tools if someone else had just told me that.

Establishing a group of students capable of building on the peer review process through formal and informal feedback (critiques) is a critical element in developing studio culture. As mentioned in the above quote the student acknowledged the value of someone else's opinion. The culture of critique was cultivated in both face-to-face sessions as well as in formal and informal Google Hangout sessions with teaching assistants and student teams. Although, not originally an individual category in the pre and post survey, evidence acknowledging the importance of critical feedback was discovered in the qualitative data from the guided self-reflections. Below is a sample quote where the student explains the opportunity to practice giving and receiving peer feedback as a process for focusing their attention on design elements.

I felt that the critique gave really valuable feedback...I would prefer something along the lines of chopping our class in half again and having a more involved peer review where we many not see some amazing projects, but we at least interact more. I did feel that the critique was extremely valuable. 
Finally, collaboration on project-based work addressing complex and open-ended problems is fundamental to studio-based learning and design thinking. Within the major category of "teamwork" several sub-themes emerged in the findings, most notably the idea that a team is strong than any one individual particular attention was paid to valuing feedback and different perspectives upon which better ideas could be crafted. The student team's ability to use platforms such as Google documents allowed for a collaborative environment where the creation of knowledge was shared and built as part of the learning process.

With regards to communication, the use of social media tools proved to be very useful. Email was discouraged while the use of a social media platform (Google + ) was employed since questions that were often duplicated could be addressed once decreasing response time, and consistency of response could be monitored with one point of reference. This tool also allowed the teaching assistants to play a role in administering the course goals and activities through responding within this platform. Clarity in communication was also necessary with regards to the freshman level population. In light of this, the teaching team worked to make content and activities highly legible within all course materials.

However, at times the use of Blackboard, Google platforms, and student's use of Facebook did complicate course data management. In addition to the Google platform, several student teams created individual team Facebook pages to share and disseminate information. Oftentimes the amount of work produced was happening at a faster rate than the student's ability to structure an organizational strategy for filing and documenting the work. Despite the struggles with organizational clarity, the interactive and decentralized capabilities of the technologies facilitated a model of digital scholarship aligned with collaborative traditions of a design studio.

In conclusion, this research has demonstrated that while refinement is needed, the use of instructional techniques and strategies informed by educational theory and research within a blended mode of instruction can effectively scale studio-based learning practices leading to the student learning within DSGN110.

\section{Future Research}

There are two important areas in which future research should be considered. First, one of the desired broader curricular outcomes with respect to student learning is the degree to which what was learned as a first year student in DSGN110 manifests itself in upper level students. Anecdotally, faculty have said that students who have been through DSGN110 course demonstrate more sophisticated team skills and have a more positive attitude towards redoing work, but more formal investigation should be done. Second, a more detailed evaluation of specific course content and activities and their alignment with desired course goals and outcomes should be pursued. 


\section{References}

Allen, E. (1980). Things learned in lab. Journal of Architectural Education, 34(2), 22-25.

Ash, S. L. \& Clayton, P. H. (2004). The articulated learning: An approach to guided reflection and assessment. Innovative Higher Education, 29(2), 137-154.

Boyer, E. L. \& Mitgang, L. D. (1996). Building Community: A New Future for Architecture Education and Practice. A Special Report. California Princeton Fulfillment Services. Retrieved on 25 April 2015 from http://eric.ed.gov/?id= ED396659

Brown, T. (2009). Change by design: how design thinking transforms organizations and inspires innovation. New York: HarperCollins.

Bryman, A. (2006). Integrating quantitative and qualitative research: how is it done? In J. W. Creswell \& V. Plano Clark (Eds.), The mixed methods reader (pp. 253-298). Thousand Oaks, CA: Sage.

Cohen, J. (1988). Statistical power analysis for the behavioral sciences. Hillsdale, NJ: Lawrence Erlbaum Associates.

Creswell, J. W. \& Plano Clark, V. L. (2011). Designing and conducting mixed methods research. Thousand Oaks, CA: Sage.

Cross, N. (2004). Expertise in design: an overview. Design Studies, 25(5), 427-441. http://doi.org/10.1016/j.destud.2004.06.002

Cuff, D. (1992). Architecture: The story of practice. Cambridge, MA: MIT Press.

Design thinking boot camp: From insights to innovation. (2015). Retrieved on 3 April 2015 from http://www.gsb.stanford.edu/exed/dtbc/

DeVellis, R. F. (2011). Scale development: Theory and applications ( $3^{\text {rd }}$ ed.). Sage.

Dym, C. L., Agogino, A. M., Eris, O., Frey, D. D., \& Leifer, L. J. (2005). Engineering design thinking, teaching, and learning. Journal of Engineering Education, 94(1), 103-120.

Ericsson, K. A., Krampe, R. T., \& Tesch-Römer, C. (1993). The role of deliberate practice in the acquisition of expert performance. Psychological Review, 100(3), 363-406.

Fain, J. A. (2005). Is there a difference between evaluation and research? The Diabetes Educator, 31(2), 150-155.

Fink, L. D. (2013). Creating significant learning experiences: an integrated approach to designing college courses ( 2 nd ed.). San Francisco, CA: Jossey-Bass

Fricke, G. (1999). Successful approaches in dealing with differently precise design problems. Design Studies, 20(5), 417-429. http://doi.org/10.1016/S0142-694X(99)00018-6

Garrison, D. R. \& Vaughan, N. D. (2007). Blended learning in higher education: Framework, principles, and guidelines. San Francisco, CA: Jossey-Bass.

Glazer, F. S. (2012). Blended learning: Across the disciplines, across the academy. New pedagogies and practices for teaching in higher education. Sterling, VA: Stylus. 
Graham, C. R., Woodfield, W., \& Harrison, J. B. (2012). A framework for institutional adoption and implementation of blended learning in higher education. The Internet and Higher Education. Retrieved on 25 April 2015 from http://www.sciencedirect.com/science/article/pii/ S1096751612000607

Guillaume, D. W. \& Khachikian, C. S. (2011). The effect of time-on-task on student grades and grade expectations. Assessment \& Evaluation in Higher Education, 36(3), 251-261.

Hatch, J. A. (2002). Doing qualitative research in educational settings. New York: State University of New York Press.

IBM Corp. (2013). IBM SPSS statistics for Windows (Version 22.0) [Windows]. Armonk NY: IBM Corp.

Jarmon, C. (2009, December). Transitioning to blended and online learning. Retrieved on 25 April 2015 from http://www.slideshare.net/PearsonLearningSolutions/transitioning-to-blendedand-online-learning-with-carolyn-jarmon-ncat-2693360

Lackney, J. (1999). A history of the studio-based learning model. Retrieved on 8 March 2012 from https://www.google.com.tr/?gfe_rd=cr\&ei=i2InVpGwFq6z8wfH6J-IDQ\&gws_rd=ssI\#q= a+history+of+the+studio-based+learning+model

MAXQDA. (2011). MAXQDA 10: Software for qualitative data analysis. Berlin, Germany: 19892012, VERBI Software-Consult-Sozialforschung GmbH. Retrieved on 25 April 2015 from http://www.maxqda.com/

Means, B., Toyama, Y., Murphy, R., Bakia, M., \& Jones, K. (2010). Evaluation of evidence-based practices in online learning: A meta-analysis and review of online learning studies. Retrieved on 25 April 2015 from www.ed.gov/about/offices/list/opepd/ppss/reports.html

Morris, S. B. \& DeShon, R. P. (2002). Combining effect size estimates in meta-analysis with repeated measures and independent-groups designs. Psychological Methods, 7(1), 105.

Moskal, P. \& Cavanagh, T. B. (2013). Scaling blended learning evaluation beyond the university. In A. G. Picciano, C. D. Dziuban, \& C. R. Graham (Eds.), Blended learning: Research perspectives (Vol. 2). London, UK: Routledge.

Moskal, P., Dziuban, C., \& Hartman, J. (2013). Blended learning: A dangerous idea? The Internet and Higher Education, 18, 15-23. http://doi.org/10.1016/j.iheduc.2012.12.001

Nagai, Y. \& Noguchi, H. (2003). An experimental study on the design thinking process started from difficult keywords: modeling the thinking process of creative design. Journal of Engineering Design, 14(4), 429-437. http://doi.org/10.1080/09544820310001606911

Picciano, A. G. (2013). Introduction to blended learning: Research perspectives II. In A. G. Picciano, C. D. Dziuban, \& C. R. Graham (Eds.), Blended learning: Research perspectives (Vol. 2). London, UK: Routledge.

Pombo, L. \& Moreira, A. (2012). Evaluation framework for blended learning courses: A puzzle piece for the evaluation process. Contemporary Educational Technology, 3(3), 201-211.

Qualtrics. (2013). Provo, UT. Retrieved on 25 April 2015 from http://www.qualtrics.com/ 
Ralph, P. \& Wand, Y. (2009). A proposal for a formal definition of the design concept. In K. Lyytinen, P. Loucopoulos, J. Mylopoulos, \& B. Robinson (Eds.), Design requirements engineering: A ten-year perspective (pp. 103-136). Berlin: Springer.

Razzouk, R. \& Shute, V. (2012). What is design thinking and why is it important? Review of Educational Research, 82(3), 330-348.

Schön, D. A. (1983). The reflective practitioner: How professionals think in action. New York: Basic Books.

Schunk, D. H. (2011). Learning theories: An educational perspective (6th ed.). Boston, MA: Pearson.

Teddlie, C. \& Yu, F. (2007). Mixed methods sampling a typology with examples. Journal of Mixed Methods Research, 1(1), 77-100.

TrueCrypt. (2014). Gibson Research Corporation. Retrieved on 25 April 2015 from https://www. $\mathrm{grc} . c o m / \mathrm{misc} /$ truecrypt/truecrypt.htm

Twigg, C. A. (2003). Improving quality and reducing cost: Designs for effective learning. Change: The Magazine of Higher Learning, 35(4), 22-29.

Vickers, R., Field, J., Melakoski, C., \& others. (2015). Media Culture 2020: Collaborative teaching and blended learning using social media and cloud-based technologies. Contemporary Educational Technology, 6(1), 62-73.

Yocom, K., Proksch, G., Born, B., \& Tyman, S. K. (2012). The built environments laboratory: An Interdisciplinary framework for studio education in the planning and design disciplines. Journal for Education in the Built Environment, 7(2), 8-25.

Zehner, R., Forsyth, G., de la Harpe, B., Peterson, F., Musgrave, E., Neale, D., \& Frankham, N. (2010). Optimising studio outcomes: Guidelines for curriculum development from the Australian studio teaching project. In ConnectED2010-2nd International Conference on Design Education, University of New South Wales, Sydney, June 28th-July 1st. Retrieved on 25 April 2015 from http://connected2010.eproceedings.com.au/papers/436.pdf

Correspondence: Sydney E. Brown, Assistant Director for Innovative Instructional Design, Department of Online and Distance Education, University of Nebraska, Lincoln, Nebraska, United States 